\title{
Laser post-ionisation combined with a high resolving power orbitrap mass spectrometer for enhanced MALDI-MS imaging of lipids
}

Citation for published version (APA):

Ellis, S. R., Soltwisch, J., Paine, M. R. L., Dreisewerd, K., \& Heeren, R. M. A. (2017). Laser post-ionisation combined with a high resolving power orbitrap mass spectrometer for enhanced MALDI-MS imaging of lipids. Chemical Communications, 53(53), 7246-7249. https://doi.org/10.1039/c7cc02325a

Document status and date:

Published: 07/07/2017

DOI:

10.1039/c7cc02325a

Document Version:

Publisher's PDF, also known as Version of record

Document license:

Taverne

Please check the document version of this publication:

- A submitted manuscript is the version of the article upon submission and before peer-review. There can be important differences between the submitted version and the official published version of record.

People interested in the research are advised to contact the author for the final version of the publication, or visit the DOI to the publisher's website.

- The final author version and the galley proof are versions of the publication after peer review.

- The final published version features the final layout of the paper including the volume, issue and page numbers.

Link to publication

\footnotetext{
General rights rights.

- You may freely distribute the URL identifying the publication in the public portal. please follow below link for the End User Agreement:

www.umlib.nl/taverne-license

Take down policy

If you believe that this document breaches copyright please contact us at:

repository@maastrichtuniversity.nl

providing details and we will investigate your claim.
}

Copyright and moral rights for the publications made accessible in the public portal are retained by the authors and/or other copyright owners and it is a condition of accessing publications that users recognise and abide by the legal requirements associated with these

- Users may download and print one copy of any publication from the public portal for the purpose of private study or research.

- You may not further distribute the material or use it for any profit-making activity or commercial gain

If the publication is distributed under the terms of Article $25 \mathrm{fa}$ of the Dutch Copyright Act, indicated by the "Taverne" license above, 
Check for updates

Cite this: Chem. Commun., 2017, 53,7246

Received 27th March 2017, Accepted 18th May 2017

DOI: $10.1039 / c 7 c c 02325 a$

rsc.li/chemcomm

\section{Laser post-ionisation combined with a high resolving power orbitrap mass spectrometer for enhanced MALDI-MS imaging of lipids $\dagger$}

\author{
S. R. Ellis, ID $\star^{a}$ J. Soltwisch, ${ }^{\text {bc }}$ M. R. L. Paine, ${ }^{a}$ K. Dreisewerd (D) bc and \\ R. M. A. Heeren (iD a
}

Coupling laser post-ionisation with a high resolving power MALDI Orbitrap mass spectrometer has realised an up to $\sim 100$-fold increase in the sensitivity and enhanced the chemical coverage for MALDI-MS imaging of lipids relative to conventional MALDI. This could constitute a major breakthrough for biomedical research.

Matrix-assisted laser desorption/ionization mass spectrometry imaging (MALDI-MSI) enables simultaneous visualization of numerous classes of biomolecules (e.g., metabolites, lipids, peptides) directly from tissue sections. ${ }^{1,2}$ MALDI-MSI of lipids has recently received increasing interest due to its possibility of differentiating and identifying different tissues and cell types (e.g., heterogeneous tumour tissues) based on the recorded lipid composition. ${ }^{3-5}$ Monitoring the changes in lipid metabolism in a spatially-resolved manner can also provide valuable insights into the biochemical pathways underlying many diseases. ${ }^{6}$ However, fundamental limitations for the applicability of standard MALDI-MSI to these biochemically relevant questions are governed by two factors: the first is the low ion yield for many classes of lipids, which can be estimated to be in the $10^{-5}$ and below range relative to generated neutrals. ${ }^{7}$ The second is inevitable ion suppression effects, in particular in the positive ion mode. ${ }^{8}$ An innovative laser-based post-ionisation (PI) approach was recently introduced to overcome these limitations. ${ }^{9}$ Using this technique, named MALDI-2, the plume of the matrix and analyte molecules generated by the standard MALDI laser is intercepted by a second PI laser beam. The initiation of secondary MALDIlike ionization processes was found to enable up to 2 orders of magnitude higher sensitivity for numerous classes of molecules

\footnotetext{
${ }^{a}$ M4I, The Maastricht Multimodal Molecular Imaging Institute, University of Maastricht, 6229 ER Maastricht, The Netherlands.

E-mail: s.ellis@maastrichtuniversity.nl

${ }^{b}$ Institute for Hygiene, University of Münster, Robert-Koch-Strasse 41, 48149 Münster, Germany

${ }^{c}$ Interdisciplinary Center for Clinical Research (IZKF), University of Münster, Domagkstrasse 3, 48149 Münster, Germany

$\dagger$ Electronic supplementary information (ESI) available. See DOI: 10.1039/ c7cc02325a
}

(e.g. many lipids, vitamins, and oligosaccharides) in both positive and negative ion modes. The success of the PI approach was found to depend critically on two factors: (i) the confinement of the plume in a buffer gas of several mbars and (ii) the use of a PI laser wavelength below the two-photon ionization threshold of the MALDI matrix. Here we build on this MALDI-2 principle and coupled a PI laser to a new ion funnel based MALDI ion source (Spectroglyph LLC, Kennewick, WA, USA) and an Orbitrap Elite mass spectrometer (Thermo Fisher Scientific, Bremen, Germany). We demonstrate that the particularly high mass resolving power of this mass analyser $(\sim 160000$ at $\mathrm{m} / \mathrm{z} 750)$ strongly enhances the chemical information density that originates from the MALDI-2-MSI method.

The experimental approach is detailed in the $\mathrm{ESI} \dagger$ (Fig. S1). Briefly, gas-phase molecules and direct MALDI ions were produced by using a frequency-tripled Q-switched Nd:YLF laser of $349 \mathrm{~nm}$ wavelength focussed to a spot of $\sim 20 \mu \mathrm{m}$ in diameter. The material desorbed from $10 \mu \mathrm{m}$ thick sagittal rat brain tissue sections coated with a norharmane matrix was cooled in a buffer gas (laboratory air) atmosphere of 5.3-6.5 mbar before being captured and transferred to the mass analyser via a dual ion funnel interface. PI was initiated via the intersection of the MALDI plume $\sim 400 \mu \mathrm{m}$ above the sample surface with light from an optical parametric oscillator laser system (NT-230, Ekspla, Vilnius, Lithuania) tuned to $280 \mathrm{~nm}$. Both lasers were operated at $100 \mathrm{~Hz}$ repetition rate with a delay of $18 \mu$ s between the two laser pulses.

The dramatic effect that was achieved using this PI approach is demonstrated in Fig. 1, showing two positive ion mode mass spectra acquired from a single $20 \mu \mathrm{m}$ wide pixel of a rat brain section using a MALDI laser pulse energy of $\sim 500 \mathrm{~nJ}$ and accumulation of 25 laser shots. At this threshold fluence only a few phosphatidylcholine (PC) signals are observed (Fig. 1a). The spectrum obtained following PI of the plume reveals a dramatic improvement in ion yields for a variety of lipid classes (Fig. 1b). Of particular interest are the strong ion signals for lipid classes that are not observed at all in Fig. 1a. For example, phosphatidylethanolamine (PE) and $\mathrm{PE}$ ether lipids are now registered at an equal or even higher abundance than PC lipids 


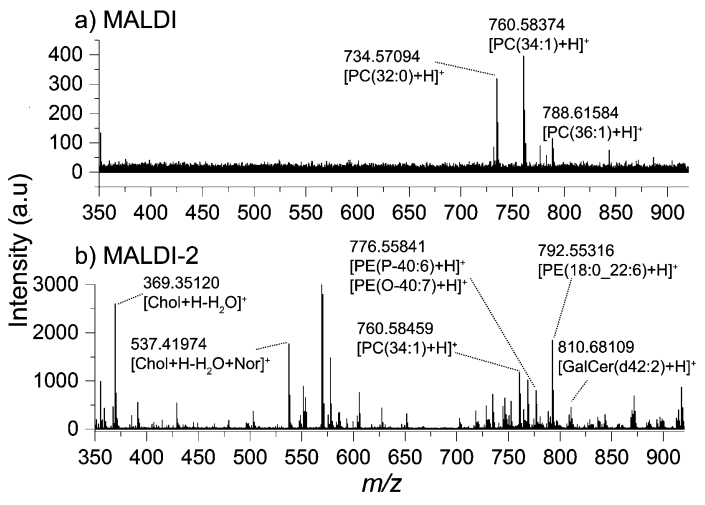

Fig. 1 Single pixel mass spectra from a sagittal rat brain section (desalted in ammonium formate, see the ESI $\dagger$ ) acquired at a pulse energy of the MALDI laser corresponding roughly to the ion detection threshold: (a) without and (b) with post-ionisation for MALDI-2. Mass errors are $<2 \mathrm{ppm}$ for all assignments. Chol: cholesterol; Nor: norharmane.

(e.g., $\left[\mathrm{PE}\left(18: 0 \_22: 6\right)+\mathrm{H}\right]^{+}$and $[\mathrm{PE}(\mathrm{P}-40: 6)+\mathrm{H}]^{+} /[\mathrm{PE}(\mathrm{O}-40: 7)+\mathrm{H}]^{+}$at $\mathrm{m} / \mathrm{z}$ values of 792.55316 and 776.55841 , respectively). In addition, ion signals with a high signal-to-noise ratio were obtained for the neutral lipids cholesterol (observed as the $\left[\mathrm{M}+\mathrm{H}-\mathrm{H}_{2} \mathrm{O}\right]^{+}$ion) and galactosylceramides (GalCer) (e.g., $\left.[\mathrm{GalCer}(\mathrm{d} 42: 2)+\mathrm{H}]^{+}\right)$. These data demonstrate that the excess of desorbed neutral molecules/ clusters can be converted efficiently to analytically useful ions via the initiation of MALDI-like secondary ionization processes. The ion funnel source design also allowed PI to be performed across a larger pressure range than previously possible. ${ }^{9}$ Initial experiments have shown that MALDI- 2 occurs efficiently at least up to 10 mbar. A somewhat longer delay of $\sim 20 \mu$ s used here compared to $\sim 10 \mu$ s at $2-3$ mbar in the previously established Q-ToF setup could indicate a higher degree of confinement and cooling efficiency of the ion funnel device. Moreover, MALDI-2 was observed across a much broader laser pulse delay range of up to several $100 \mu \mathrm{s}$, compared to $30 \mu \mathrm{s}$ for the Q-ToF setup. ${ }^{9}$

The following MALDI and MALDI-2 MSI data were acquired sequentially from the same tissue section $(\sim 25$ shots per pixel with an interleaved $100 \mu \mathrm{m}$ step size) using optimised MALDI fluences to directly compare the two methods (see the ESI $\dagger$ ). Tandem MS spectra of discussed lipids are provided in Fig. S3-S6 (ESI $\dagger)$. The average mass spectra covering the phospholipid range between $\mathrm{m} / \mathrm{z} 650$ and 950 acquired across both MSI datasets are compared in Fig. 2a. With the optimized MALDI fluence strong lipid ion signals were obtained using both MALDI and MALDI-2. Consistent with the previous data upon PI notably different profiles are obtained..$^{9}$ PE lipids were the biggest beneficiary of PI. The signals for protonated PE molecules generally increased up to $\sim 50-80$ fold, whereas those for the alkali adduct of PEs were found to increase about $2-5$-fold. Fig. $2 \mathrm{~b}$ shows the MALDI-2 ion image of $\left[\mathrm{PE}\left(18: 0 \_22: 6\right)+\mathrm{H}\right]^{+}$along with the average MALDI and MALDI-2 ion intensities. This lipid was found to be primarily present in the white matter of the brain. Another lipid with $\sim 50$-fold improvement is shown in Fig. 2c. This ion with $\mathrm{m} / \mathrm{z}$ 746.57015 shows a relatively homogenous distribution throughout the brain section. Based on the accurate mass and a neutral loss of 141 Da upon low-energy collision-induced dissociation

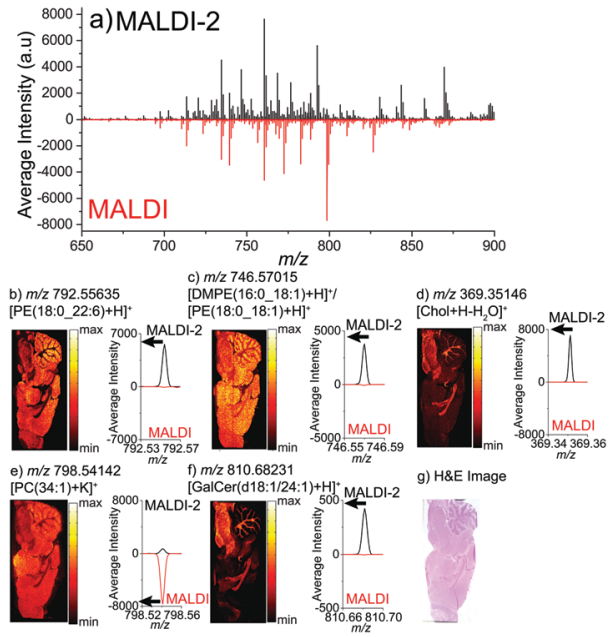

Fig. 2 (a) Summed MALDI and MALDI-2 spectra acquired from a sagittal rat brain tissue section in the positive ion mode (cf. Fig. S2, ESI $\dagger$ for a full mass spectrum). (b-f) lon images of selected lipids along with the corresponding MALDI and MALDI-2-derived signal traces. Black arrows indicate which dataset was used to produce the MSI image to the left. Mass errors are $<2$ ppm. (g) H\&E stain obtained from the same tissue section after MSI

(CID) a strong contributor to this signal was assigned to [PE(18:0_18:1)+H] $]^{+}$. Further examination of the MS/MS spectrum revealed an abundant neutral loss of $169 \mathrm{Da}$. Using accurate mass combined with MS/MS this neutral loss was consistent with the loss of $N, N$-dimethylethenamine and thus concluded to be a dimethyl-PE (DMPE) lipid (Fig. S3, ESI $\dagger$ ). ${ }^{10}$ Further neutral losses suggesting also the presence of 16:0 and 18:1 fatty acids led us to believe that the detected ions also arose via dissociation of PC molecules induced by the MALDI/ MALDI-2 process. This assumption was corroborated upon analysis of a $\mathrm{PC}(14: 0 / 14: 0)$ standard which revealed the presence of an $\left[\mathrm{M}-\mathrm{CH}_{3}\right]^{+}$ion (Fig. S7, ESI $\dagger$ ). Analogous DMPE signals were also observed under conventional MALDI conditions but at sizably reduced levels. We attribute the increase in the DMPE signal to the enhanced ionisation of MALDI-generated DMPE neutrals by MALDI-2 and/or MALDI-2 induced fragmentation of PC to the corresponding DMPE. In both cases fragmentation likely follows the formation of an anionic adduct (e.g., with chloride or matrix anions). ${ }^{11}$ Therefore, part of the $m / z 746.57015$ ion population is attributed to fragmentation of the abundant PC(16:0_18:1) lipids with analogous DMPE lipids observed for other PCs. MALDI-2 also provided a dramatic improvement in the detection of the $[\mathrm{M}+\mathrm{H}-$ $\left.\mathrm{H}_{2} \mathrm{O}\right]^{+}$ion of cholesterol (neither this ion nor the intact molecular form was detected using conventional MALDI (Fig. 2d) and a slight $(\sim 1.5-2 \times)$ increase in protonated PC lipids (data not shown)). Surprisingly, the latter increase was correlated with a strong reduction in the intensity of the corresponding $[\mathrm{M}+\mathrm{Na}]^{+}$and $[\mathrm{M}+\mathrm{K}]^{+}$adducts of the same PC species (Fig. 2e). We believe that the loss of alkali adducts arises from a combination of PC-matrix adduct formation, the fragmentation of some PC lipids to the DMPE analogues (see above) and the creation of an excess of protons upon matrix PI leading to favoured formation of $[\mathrm{M}+\mathrm{H}]^{+}$ ions. We note that this strong loss of alkali adducts was not observed in the QToF implementation of MALDI- $2^{9}$ and 
speculate that these elude to the differences in the plume chemistry/gas-dynamics occurring in the two vastly different ion sources. As a final example, Fig. $2 \mathrm{f}$ shows the $\sim 50$-fold improvement for protonated [GalCer(d18:1/24:1)+H] $]^{+}$. As expected, this sphingolipid is found primarily in the myelin-rich white matter areas of the brain. Although the protonated form was essentially absent in the conventional MALDI spectra, we note that the $[\mathrm{M}+\mathrm{K}]^{+}$ion of GalCer(d18:1/24:1) was observed with similar abundance to the protonated MALDI-2-derived ion. In addition to the protonated and cationised lipid ions a plethora of higher mass signals above $\mathrm{m} / \mathrm{z} 850$ and below $\mathrm{m} / \mathrm{z} 600$ are observed in the MALDI-2 spectra. Tandem-MS experiments revealed that a notable fraction of these ion species represents analyte-matrix adducts (Fig. S9, ESI $\dagger$ ). The adduct formation is also well visible in the example of the cholesterol-norharmane adduct signal in Fig. 1b. With lower intensities, many of these lipid-matrix adduct peaks were also found in the conventional MALDI mass spectra, indicating a general tendency of the norharmane matrix towards adduct formation under the given elevated pressure conditions. Furthermore, the observation of similar adducts was made in the negative ion mode (Fig. S10, ESI $\dagger$ ).

The advantage of the enabled high mass resolving power in combination with the increased biochemical information content of MALDI-2 is illustrated in Fig. 3. Under standard MALDI conditions, within the shown $\sim 130 \mathrm{mDa}$-wide $\mathrm{m} / \mathrm{z}$ window only one ion signal at $m / z 782.567$ is detected. This signal can be assigned to a mixture of $[\mathrm{PC}(36: 4)+\mathrm{H}]^{+}$and $[\mathrm{PC}(34: 1)+\mathrm{Na}]^{+}$. These ions have a mass difference of only $2.4 \mathrm{mDa}$ and cannot be resolved even using this instrument. Interestingly, upon using MALDI-2 this peak however shifts to a slightly higher mean $\mathrm{m} / \mathrm{z}$ value of 782.56958 ; this finding can be rationalised by a relative reduction in $[\mathrm{PC}(34: 1)+\mathrm{Na}]^{+}$and a simultaneous increase in $[\mathrm{PC}(36: 4)+\mathrm{H}]^{+}$. Using MALDI-2, 3 additional isobaric ions at $\mathrm{m} / \mathrm{z}$ values of $782.59716,782.60629$ and 782.65041 are also detected with MALDI-2 (the upper trace in Fig. 3). Based on the accurate mass and their observed CID fragments (Fig. S8, ESI $\dagger$ ) these ion species can be assigned to $\left[\mathrm{PE}(\mathrm{P}-40: 4){ }^{13} \mathrm{C}_{2}+\mathrm{H}\right]^{+} /\left[\mathrm{PE}(\mathrm{O}-40: 5){ }^{13} \mathrm{C}_{2}+\mathrm{H}\right]^{+}, \quad[\mathrm{PE}(\mathrm{P}-40: 3)+\mathrm{H}]^{+} /$ $[\mathrm{PE}(\mathrm{O}-40: 4)+\mathrm{H}]^{+}$and $[\mathrm{GalCer}(\mathrm{d} 18: 1 / 22: 1)+\mathrm{H}]^{+}$, respectively.

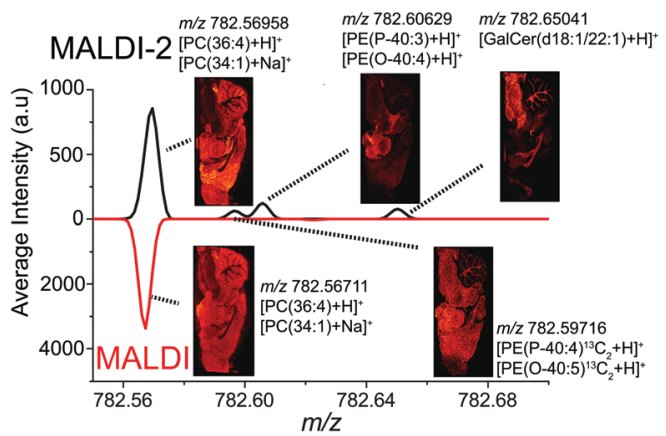

Fig. 3 Zoomed section of the MALDI (bottom trace) and MALDI-2 (top trace) spectra shown in Fig. $2 a$ and the corresponding images of isobaric ions. Mass errors are less than $2 \mathrm{ppm}$ with the exception of $[\mathrm{PC}(34: 1)+\mathrm{Na}]^{+}$ in MALDI-2 (3.4 ppm) and $[\mathrm{PC}(36: 4)+\mathrm{H}]^{+}$for MALDI $(-2.7 \mathrm{ppm})$, see the text for explanation.
Of particular analytical interest is the ability to resolve the unsaturated $[\mathrm{PE}(\mathrm{P}-40: 3)+\mathrm{H}]^{+} /[\mathrm{PE}(\mathrm{O}-40: 4)+\mathrm{H}]^{+}$lipids from the related lipid ion containing one less double bond but two ${ }^{13} \mathrm{C}$ atoms. Also, the ability to detect PE lipids in the positive ion mode with high sensitivity provides complementary lipid detection capabilities relative to positive ion MALDI.

We evaluated the advantage of MALDI-2-MSI coupled with the high resolving power of the Orbitrap also for the negative ion mode. Representative results are provided in Fig. 4. Structural assignments were supported by MS/MS experiments (Fig. S11-S15, ESI $\dagger$ ). PI resulted in up to an order of magnitude improvement for many phospholipid-derived ions (Fig. 4a). For example, the abundances of deprotonated phosphatidylserine PS(18:0_22:6) (Fig. 4b) and PE(P-34:1) (Fig. 4c) increased by $\sim 3$ and 12-fold, respectively. Phosphatidic acid (PA) signals that may arise from both endogenous PA and fragmentation of other lipids increased by $\sim 8$-fold under MALDI- 2 conditions. This could constitute one reason why these ion species were observed relatively homogenously throughout the brain (e.g., [PA(16:0_18:1)-H] $]^{-}$, Fig. 4d). Neutral galactosylceramides (e.g., [GalCer(d40:1)-H $]^{-}$, Fig. 4e) which were barely detected by regular MALDI increased by up to two orders of magnitude with MALDI-2. The two major exceptions to this general trend are phosphatidylinositols (PIn) and sulfatides (ST). The $[\mathrm{M}-\mathrm{H}]^{-}$ ion signal of the particularly well ionizable phosphatidylinositol showed an $\sim 25 \%$ decrease with MALDI-2, whereas STs, (e.g., $\left.[\mathrm{ST}(\mathrm{d} 18: 1 / 24: 1)-\mathrm{H}]^{-}\right)$experienced an even more dramatic reduction in the signal (Fig. 4f). This finding is in contrast to the previous Q-ToF studies in which the same norharmane matrix was used. ${ }^{9}$ Similar to the positive ion mode we speculate that the decrease could be related to the formation of adducts,

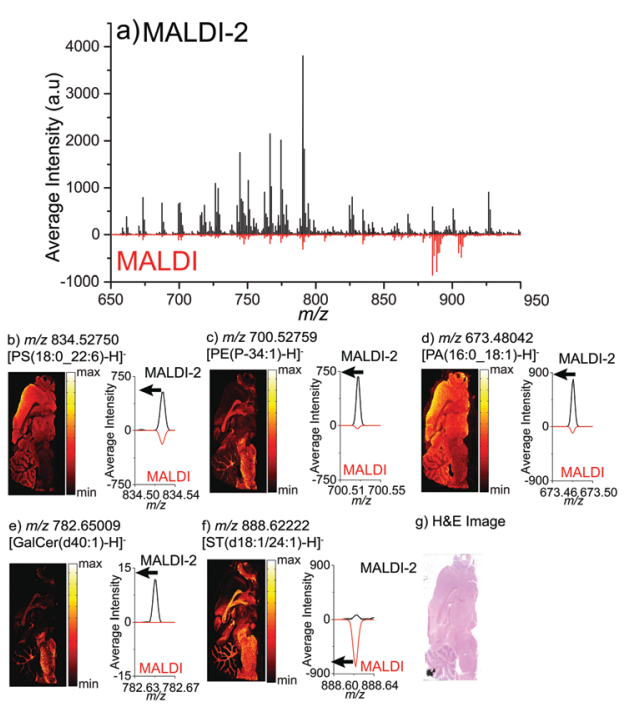

Fig. 4 (a) Summed MALDI and MALDI-2 mass spectra acquired from a sagittal rat brain tissue section in the negative ion mode. (cf. to Fig. S16, $\mathrm{ESI} \dagger$ for a full mass spectrum). (b-f) lon images of selected lipids along with the corresponding MALDI and MALDI-2 signal traces. Black arrows indicate which dataset was used to produce the MSI image to the left. Mass errors are $<2$ ppm. (g) H\&E stain obtained from the same tissue section after the MSI measurement. 


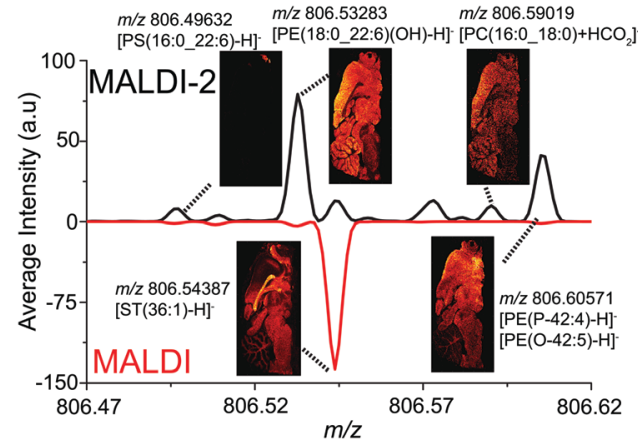

Fig. 5 Zoomed section of the MALDI (bottom trace) and MALDI-2 (top trace) spectra shown in Fig. $4 a$ and the corresponding images of isobaric ions. Mass errors are $<2.5 \mathrm{ppm}$ for all assignments.

potentially selective fragmentation or different plume dynamics within the ion funnel-based source geometry. However, it appears to not be related to the used power of the PI laser pulse. A similar relative decrease was observed if the PI pulse energy was lowered from $800 \mu \mathrm{J}$ to $50 \mu \mathrm{J}$ (Fig. S17, ESI $\dagger$ ). These results show that also in the negative ion mode an overall significantly increased chemical coverage is obtained with PI of desorbed neutral molecules/clusters.

The added biochemical information resulting from the coupling of negative-ion mode MALDI-2 and high resolving power MSI is further exemplified in Fig. 5. These data reveal the detection of 5 isobaric lipids within an $\sim 130 \mathrm{mDa}$-wide $\mathrm{m} / \mathrm{z}$ window, several of which are only observed at sizable intensity with PI. Using the accurate mass and MS/MS (Fig. S18, ESI $\dagger$ ) their species can be assigned to $\left[\operatorname{PS}\left(16: 0 \_22: 6\right)-\mathrm{H}\right]^{-}, \quad\left[\mathrm{PE}\left(18: 0 \_22: 6\right)(\mathrm{OH})-\mathrm{H}\right]^{-}, \quad[\mathrm{ST}(\mathrm{d} 36: 1)-\mathrm{H}]^{-}$, $\left[\mathrm{PC}\left(16: 0 \_18: 0\right)+\mathrm{HCO}_{2}\right]^{-}$and $[\mathrm{PE}(\mathrm{P}-42: 4)-\mathrm{H}]^{-} /[\mathrm{PE}(\mathrm{O}-42: 5)-\mathrm{H}]^{-}$. In contrast, using conventional MALDI-MSI only the ST was detected as a major signal. The detection of $\left[\mathrm{PC}+\mathrm{HCO}_{2}\right]^{-}$was confirmed by accurate mass $(-1.8 \mathrm{ppm}$ error $)$ and $\mathrm{MS} / \mathrm{MS}$ revealing an abundant loss of 60 Da corresponding to the neutral loss of methyl formate. Via registering PCs in the negative ion mode the detection of all phospholipid classes in a single acquisition was accomplished. An important point to consider is the limited number (25) of laser shots acquired at each position due to the $100 \mathrm{~Hz}$ operation of the MALDI-2 laser to give a scan time of $\sim 1$ pixel per second. A similar negative ion mode MALDI analysis at $1 \mathrm{kHz}(\sim 250$ shots per position) yielded $\sim 3-4$ times the signal compared to MALDI at $100 \mathrm{~Hz}$. Nonetheless MALDI-2 still provided superior sensitivity for most lipid classes, and its advantage would also scale with the repetition rate using a faster PI laser.
In summary, the combination of MALDI-2 with an elevated pressure ion funnel-based ion source on a high mass resolving power analyser offers impressive new opportunities for sensitive MALDI-MS imaging of complex chemical systems. Importantly, in both the positive and negative ion modes a much wider range of different lipid classes is registered in a single acquisition and all lipids detected with MALDI are also observed with MALDI-2 to varying extents. Notably, the reduction of some molecular ion signals upon PI mostly concerns lipid species that are already well detectable with standard MALDI (PC, ST and PIn). This work also provided further insight into the differences in gas-phase reactions between MALDI and MALDI-2 and indicated that a micro-reactor is formed under elevated pressure conditions enabling a multitude of competing charge transfer reactions. The translation of this innovative approach with increased sensitivity to further physiologically relevant biomolecule classes and biomedical/clinical applications can in the future pave the way for MALDI-MSI studies on the nanoscale.

This work has been made possible with the financial support of the Dutch province of Limburg. The Maastricht University gratefully acknowledges financial support from ITEA and RVO by means of project numbers ITEA151003/ITEA 14001. Financial support from the German Science Foundation (grants DR 416/ 12-1, DR 416/13-1, SO 976/2-1, SO 976/3-1, SO 976/4-1) and the IZKF (Drei2/018/17) is gratefully acknowledged. The authors are grateful to Yury Tsybin and Konstantin Nagornov (Spectroswiss) for their help with data analysis and Rob Satink (Acal BFi) and Mikhail Belov (Spectroglyph) for technical support.

\section{Notes and references}

1 L. A. McDonnell and R. M. A. Heeren, Mass Spectrom. Rev., 2007, 26, 606-643.

2 J. L. Norris and R. M. Caprioli, Chem. Rev., 2013, 113, 2309-2342.

3 E. E. Jones, T. W. Powers, B. A. Neely, L. H. Cazares, D. A. Troyer, A. S. Parker and R. R. Drake, Proteomics, 2014, 14, 924-935.

4 L. Jiang, K. Chughtai, S. O. Purvine, Z. M. Bhujwalla, V. Raman, L. Paša-Tolić, R. M. A. Heeren and K. Glunde, Anal. Chem., 2015, 87, 5947-5956.

5 S. Guo, Y. Wang, D. Zhou and Z. Li, Sci. Rep., 2014, 4, 5959.

6 K. A. Zemski Berry, J. A. Hankin, R. M. Barkley, J. M. Spraggins, R. M. Caprioli and R. C. Murphy, Chem. Rev., 2011, 111, 6491-6512.

7 A. A. Puretzky and D. B. Geohegan, Chem. Phys. Lett., 1998, 286, 425-432.

8 J. Schiller, R. Süss, J. Arnhold, M. Müller, M. Petković, H. Spalteholz, O. Zschörnig and K. Arnold, Prog. Lipid Res., 2004, 43, 449-488.

9 J. Soltwisch, H. Kettling, S. Vens-Cappell, M. Wiegelmann, J. Müthing and K. Dreisewerd, Science, 2015, 348, 211-215.

10 M. Bilgin, D. F. Markgraf, E. Duchoslav, J. Knudsen, O. N. Jensen, A. I. P. M. de Kroon and C. S. Ejsing, Biochim. Biophys. Acta, Mol. Cell Biol. Lipids, 2011, 1811, 1081-1089.

11 K. Ekroos, C. S. Ejsing, U. Bahr, M. Karas, K. Simons and A. Shevchenko, J. Lipid Res., 2003, 44, 2181-2192. 